\title{
RANCANG BANGUN MESIN PENGUPAS KULIT LADA MENGGUNAKAN CUTTER RUBBER PAD
}

\author{
Susilawati $^{1}$, Rivandra Rezani ${ }^{2}$, Imam Mutaqim ${ }^{3}$, Suparman Sutaryat ${ }^{4}$ \\ 1,3,4Program Studi Pemeliharaan Mesin Politeknik Negeri Subang; ${ }^{2}$ Program Studi Pendidikan Teknik Mesin Fakultas Teknik \\ Universitas Negeri Yogyakarta \\ Email: usie@polsub.ac.id
}

\begin{abstract}
Surian Subdistrict, especially in Mekarsari village, has the largest potential of pepper production in Sumedang Regency. The full potential has not been achieved due to lack of mechanization in the pepper production. Currently, the peeling process of peppercorns uses manual hand rubbing, which is inefficient and causing tiredness and skin irritation. The purpose of this research is to design and build a peppercorns peeling machine to increase productivity. The design process used Autodesk Inventor 2015 CAD software. The machine building process comprised of design actualization, Work Preparation planning, tools and materials preparation, machining and fabrication process and test run. The result of the design is a peeling machine having dimensions $(l \times w \times h)$ of $993 \times 590 \times 670 \mathrm{~mm}$. The machine is equipped with a $5.5 \mathrm{HP}$ and $3600 \mathrm{rpm}$ motor drive which yields in $28 \mathrm{~kg}$ /hour pepper production capacity. The working principle of this machine is to grind the peppercorns in the filter and then the cutter cuts and separates the pepper seeds from its shell.
\end{abstract}

Keywords: pepper, peeler, machine

\begin{abstract}
ABSTRAK
Kecamatan Surian memiliki potensi penghasil lada terbesar di Kabupaten Sumedang, khususnya di Desa Mekarsari (Yosini, 2018: 105-115). Permasalahan petani lada adalah masih secara manual dalam pengupasan kulit lada. Proses yang dilakukan hanya menggunakan kedua telapak tangan dalam menggosok buah lada sehingga memerlukan waktu yang lama dan menyebabkan kelelahan dan iritasi pada kulit telapak tangan. Tujuan penelitian ini adalah merancang dan membuat mesin pengupas kulit lada agar dapat membantu petani lada dalam meningkatkan produktivitasnya. Teknik perancangan menggunakan software Autodesk Inventor 2015. Proses manufaktur dilakukan melalui tahapan pembacaan desain, pembuatan work preparation, persiapan alat dan bahan, proses manufaktur hingga uji kinerja. Hasil penelitian yaitu dihasilkan mesin pengupas kulit lada dengan dimensi panjang $993 \mathrm{~mm}$, lebar 590 mm dan tinggi 670 mm dengan motor 5,5 HP dan putaran 3.600 rpm dan kapasitas $28 \mathrm{~kg} / \mathrm{jam}$. Prinsip kerja mesin ini yaitu menggiling lada yang terdapat pada filter kemudian cutter bertabrakan dengan lada sampai terpisah dengan kulitnya.
\end{abstract}

Kata kunci: lada, mesin, pengupas kulit lada

\section{PENDAHULUAN}

Salah satu rempah-rempah yang paling banyak diekspor Indonesia adalah lada (piper nigrum L). Di Indonesia, salah satu daerah yang memproduksi lada adalah di Kecamatan Surian Desa Sukasari Kabupaten Sumedang, di mana lada merupakan salah satu potensi unggulannya (Yosini Deliana, 2018: 105-115). Lada di Indonesia diklasifikasikan ke dalam dua jenis yaitu lada hitam dan lada putih. Lada hitam dapat dikeringkan bersama kulitnya (tanpa pengupasan) sedangkan lada putih dapat dikeringkan setelah melalui perendaman dan pengupasan (Almizan, 2017: 13-18). Jenis produk lada yang dihasilkan oleh petani tergantung pada cara dan alat pengolahan (Rusli, 1996: 188-194). Permasalahan di lapangan yang sering dihadapi oleh petani lada di Desa Mekarsari adalah proses pengupasan kulit lada dilakukan secara manual atau tradisional. Setelah dilakukan perendaman selama 8-14 hari, kemudian dilakukan proses pengupasan dengan cara menggosok-gosokan 
kedua telapak tangan secara bersentuhan hingga kulit lada terlepas. Proses pengupasan tersebut memerlukan waktu yang lama serta menyebabkan iritasi pada telapak tangan dan pegal-pegal pada bagian tubuh tertentu. Hal ini menjadikan produktivitas petani lada rendah dan mutu lada yang dihasilkan kurang bagus, karena lada menjadi bau dan kandungan minyak atsiri menjadi rendah akibat proses perendaman (Sri Usmiati, 2006: 80-86).

Pengolahan lada secara tradisional juga memiliki resiko produk terkontaminasi oleh mikroorganisme, misalnya pada saat proses perendaman dengan kualitas air yang kurang memadai dan waktu perendaman yang lama ( \pm 14 hari) dapat menyebabkan kontaminasi dan bau serta menurunnya minyak atsiri yang dihasilkan pada produk (Tatang Hidayat, 2009: 77-91). Untuk mengatasinya, kontaminasi dapat dikurangi dengan perendaman dalam air yang mengalir (Sri Usmiati, 2006: 80-86). Sedangkan menurut Maizar Rizki (2015: 1923) proses pengupasan lada secara tradisional menyebabkan pekerja mengalami berbagai macam keluhan, seperti memerlukan waktu yang lama, pergelangan tangan dan bahu harus bergerak memutar agar bersinggungan langsung dengan lada dan menekan lada yang memiliki getah tanpa menggunakan sarung tangan.

Berbagai upaya yang telah dilakukan dalam membantu proses pengupasan kulit lada diantaranya pembuatan mesin pengupas lada tipe silinder putaran vertikal (Suhendra, 2010). Hasil penelitian diperoleh bahwa mesin dapat memproses pengupasan lada tanpa perlakuan perendaman, uji kinerja dihasilkan bahwa kecepatan silinder pengupas 352 rpm, panjang silinder pengupas $5 \mathrm{~cm}$ dengan celah 3,2 $\mathrm{mm}$. Kinerja terbaik dihasilkan pengupasan 83,2\% dengan kapasitas 10,3 kg/jam dan kerusakan 11,2\%. Lebar celah dan panjang silinder pengupas juga berpengaruh terhadap proses pengupasan, di mana semakin sempit celah dan silinder pengupas yang panjang maka tekanan menjadi lebih besar dan waktu pengupasan menjadi lebih lama sehingga menyebabkan semakin banyak lada yang rusak. Sedangkan bila lebar celah terlalu renggang dan panjang silinder yang pendek maka semakin banyak lada yang tidak terkupas. Kelemahan dari mesin tersebut yaitu kapasitas mesin masih relatif rendah kerena desain hopper yang membuat lada sulit memasuki celah pengupas, serta diperlukan perbaikan pada rancangan inlet dengan penambahan mekanisme penekan agar lada yang rusak dan tidak terkupas dapat diproses kembali atau tidak terbuang. Selain itu diperlukan karet yang lebih elastis untuk melapisi silinder pengupas untuk meningkatkan kinerja pengupasan.

Penelitian yang dilakukan oleh Firlya Rosa (2018: 177-183) dengan judul Rancang Bangun Pengupas Biji Lada menggunakan Sistem Crusher, dihasilkan mesin pengupas lada dengan sistem crusher yang berdimensi 600 x 600 x $800 \mathrm{~mm}$ dengan sistem pemindah tenaga menggunakan bevel gear dengan kecepatan putar piringan $15 \mathrm{rpm}$ dan sumber energy berupa motor listrik dan reducer. Diameter inlet sebesar $30 \mathrm{~mm}$ dan diameter piringan sebesar $400 \mathrm{~mm}$ dan kemiringan piringan sebesar $0,68^{\circ}$ atau $1,13 \%$. Persentase lada terkelupas sempurna sebesar $89 \%$ selama 6 menit dengan efisiensi mesin 92\% dan kapasitas mesin $1 \mathrm{~kg} / \mathrm{jam}$. Kelemahan dari mesin ini yaitu kapasitas yang masih rendah yaitu hanya $1 \mathrm{~kg} / \mathrm{jam}$ hal tersebut disebabkan karena hopper dan diameter inlet sangat kecil sehingga berpengaruh terhadap berat biji lada yang dimasukkan. Semakin besar diameter inlet maka kapasitas mesin akan semakin besar.

Pembuatan mesin pengupas kulit lada menggunakan cutter rubber pad ini bertujuan untuk menghasilkan mesin yang dapat mengupas kulit lada tanpa melalui proses perendaman terlebih dahulu selama (8-14 hari), menciptakan mesin pengupas kulit lada dengan kapasitas yang besar. 


\section{METODE}

Tahapan penelitian dapat dilihat pada Gambar 1.

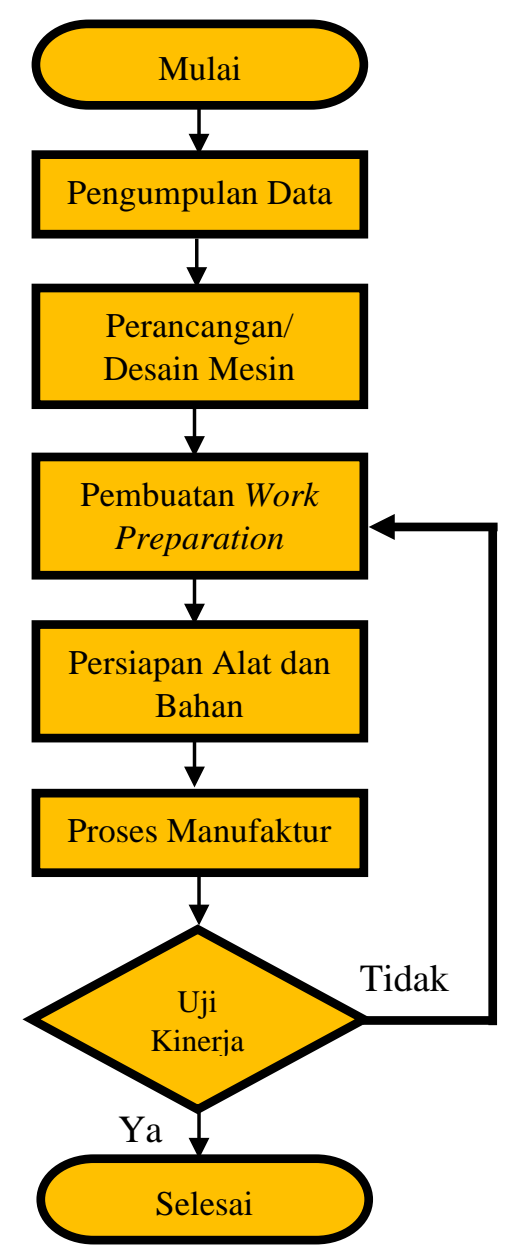

Gambar 1. Diagram Alir Penelitian

(Sumber: Dokumentasi Pribadi)

Penelitian ini dimulai dengan pengumpulan data melalui studi literatur, observasi dan wawancara. Kemudian dilanjutkan dengan pembuatan/perancangan desain mesin pengupas kulit lada menggunakan cutter rubber pad dengan software Autodesk Inventor 2015. Desain mesin ini termasuk ke dalam desain pengembangan dari model yang sudah ada. Menurut Ashby (2005) desain pengembangan merupakan desain yang mengambil konsep dari desain yang sudah ada sebelumnya kemudian dikembangkan secara bertahap terhadap prinsip kerja dan kinerja suatu produk. Proses desain memiliki tiga tahapan, yakni: konsep desain mencakup spesifikasi dan identifikasi material, penentuan fungsi dan prinsip kerja produk. Tahap kedua yaitu embodiment process atau tahap perwujudan desain mencakup pengembangan tata letak, skala bentuk, analisis perakitan dan optimalisasi fungsi. Tahap ketiga yaitu detail desain mencakup pemeriksaan komponen, pemilihan material, optimalisasi kinerja dan biaya (Susilawati, 2019: 53-58). Setelah pembuatan desain, langkah selanjutnya adalah pembuatan work preparation (WP) di mana WP merupakan lembar rencana kerja yang harus disiapkan/dibuat sebelum melakukan praktik menggunakan mesin, tujuannya untuk meminimalisir kesalahan (Rivandra Rezani, 2018: 40).

Langkah selanjutnya yaitu persiapan alat dan bahan untuk efisiensi proses pengerjaan, lalu dilanjutkan dengan proses manufaktur. Proses manufaktur adalah sebuah prosedur yang dirancang untuk menghasilkan perubahan fisik dan atau kimia pada pekerjaan material untuk meningkatkan nilai jual material tersebut (Susilawati, 2019: 21-25). Proses manufaktur terdiri dari pembacaan gambar dan pemahaman work preparation, pengukuran, pemotongan dan penyambungan bahan, perakitan/assembly, dan finishing. Tahapan selanjutnya yakni uji kinerja untuk mengetahui apakah mesin dapat bekerja dengan baik atau mengalami kendala. Apabila pada saat uji kinerja mesin sudah berjalan dengan optimal maka penelitian telah selesai, namun apabila mengalami kegagalan atau ada kendala maka perlu diindentifikasi kendala/permasalahannya dan dicari solusi pemecahannya. 


\section{HASIL DAN PEMBAHASAN}

Hasil perancangan mesin pengupas kulit lada menggunakan cutter rubber pad adalah sebagai berikut:

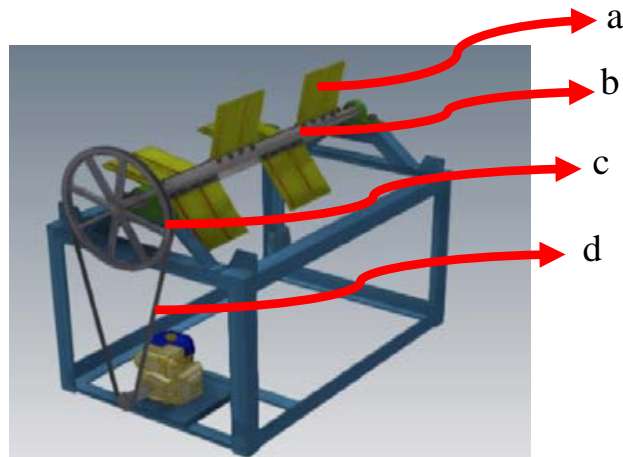

Gambar 2. Inner Sub Assembly 1 Mesin Pengupas Kulit Lada menggunakan Cutter Rubber Pad (Sumber: Dokumentasi Pribadi)

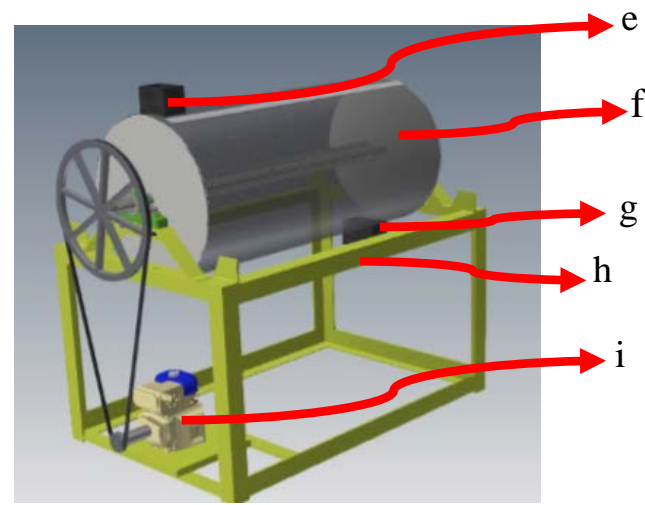

Gambar 3. Inner Sub Assembly 2 Mesin Pengupas Kulit Lada menggunakan Cutter Rubber Pad (Sumber: Dokumentasi Pribadi)

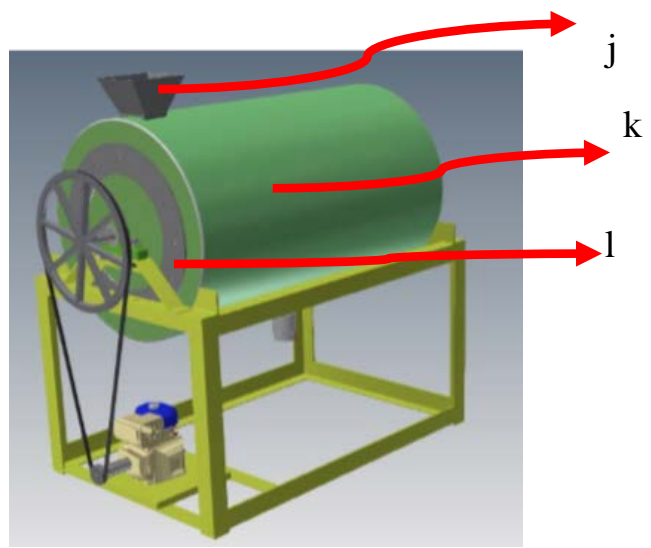

Gambar 4. Full Assembly Mesin Pengupas Kulit Lada menggunakan Cutter Rubber Pad (Sumber: Dokumentasi Pribadi)
Keterangan:

Tabel 1. Spesifikasi Desain Mesin Pengupas Kulit Lada menggunakan Cutter Rubber Pad

\begin{tabular}{|c|c|c|c|}
\hline Kode & Nama & Dimensi & Material \\
\hline $\mathrm{a}$ & $\begin{array}{l}\text { Cutter } \\
\text { rubber } \\
\text { pad }\end{array}$ & $\begin{array}{l}\text { Panjang } 193 \text { mm, } \\
\text { lebar } 98 \text { mm }\end{array}$ & Rubber \\
\hline b & $\begin{array}{l}\text { Poros } \\
\text { dan } \\
\text { dudukan } \\
\text { cutter }\end{array}$ & $\begin{array}{l}\text { Panjang poros } \\
1100 \mathrm{~mm}, \\
\text { panjang dudukan } \\
800 \mathrm{~mm} \text { tebal } 3 \\
\mathrm{~mm}\end{array}$ & ST. 37 \\
\hline c & Pulley & $\begin{array}{l}\varnothing \text { luar } 355 \text { mm, } \\
\varnothing \text { dalam } 20 \text { mm }\end{array}$ & $\begin{array}{l}\text { Alumu- } \\
\text { nium cor }\end{array}$ \\
\hline d & $V$-Belt & 70 inch & $\begin{array}{l}\text { Canvas, } \\
\text { rubber, } \\
\text { cord }\end{array}$ \\
\hline e & $\begin{array}{l}\text { Saluran } \\
\text { input }\end{array}$ & $\begin{array}{l}\text { Panjang } 66 \mathrm{~mm} \text {, } \\
\text { lebar } 96 \mathrm{~mm}\end{array}$ & ST. 37 \\
\hline $\mathrm{f}$ & Filter & $\begin{array}{l}\text { Panjang } 896 \mathrm{~mm} \text {, } \\
\varnothing 440 \mathrm{~mm}\end{array}$ & $\begin{array}{l}\text { Stainless } \\
\text { steel }\end{array}$ \\
\hline g & $\begin{array}{l}\text { Output } \\
\text { filter }\end{array}$ & $\begin{array}{l}\text { Panjang } 70 \mathrm{~mm} \text {, } \\
\text { lebar } 120 \mathrm{~mm}\end{array}$ & ST. 37 \\
\hline $\mathrm{h}$ & Rangka & $\begin{array}{l}\text { Panjang } 993 \mathrm{~mm} \text {, } \\
\text { lebar } 590 \mathrm{~mm} \text {, } \\
\text { tinggi } 670 \mathrm{~mm}\end{array}$ & $\begin{array}{l}\text { Besi siku } \\
\text { ST. } 37 \text {, } \\
5 \times 5 \mathrm{~cm} \\
\end{array}$ \\
\hline $\mathrm{i}$ & $\begin{array}{l}\text { Motor } \\
\text { Bensin } \\
\end{array}$ & 5,5 HP, 3600 rpm & Besi \\
\hline $\mathrm{j}$ & Hopper & $\begin{array}{l}\text { Bagian luar: } \\
\text { panjang } 230 \mathrm{~mm} \text {, } \\
\text { lebar } 230 \mathrm{~mm} . \\
\text { Bagian dalam: } \\
\text { panjang } 115 \mathrm{~mm} \text {, } \\
\text { lebar } 75 \mathrm{~mm}\end{array}$ & $\begin{array}{l}\text { Besi plat } \\
\text { ST. } 37 \\
\text { tebal } 3 \\
\mathrm{~mm}\end{array}$ \\
\hline $\mathrm{k}$ & Drum & $\begin{array}{l}\text { Panjang } 930 \mathrm{~mm} \text {, } \\
\varnothing 580 \mathrm{~mm}, \\
\text { kapasitas } 200 \\
\text { liter }\end{array}$ & Plat besi \\
\hline l & $\begin{array}{l}\text { Penutup } \\
\text { drum }\end{array}$ & $\begin{array}{l}\varnothing \text { luar } 460 \text { mm, } \\
\varnothing \text { dalam } 300 \\
\text { mm }\end{array}$ & Plat besi \\
\hline
\end{tabular}

Proses manufaktur mesin pengupas kulit lada menggunakan cutter rubber pad, melalui beberapa tahapan yakni pembacaan serta pemahaman gambar kerja dan work preparation (WP), pengukuran bahan, pemotongan bahan, proses penyambungan, proses perakitan, dan finishing. Pembacaan dan pemahaman gambar kerja yang baik dilakukan agar proses pengerjaan sesuai dengan rancangan yang telah 
dibuat oleh drafter. Sedangkan pemahaman yang baik akan work preparation dibutuhkan agar proses pengerjaan dapat selesai secara efektif dan efisien. Alat dan bahan yang digunakan dalam pembuatan mesin pengupas kulit lada menggunakan cutter rubber pad yakni:

Tabel 2. Alat dan Bahan yang Digunakan

\begin{tabular}{|c|c|c|c|}
\hline No. & Alat & No. & Bahan \\
\hline 1. & $\begin{array}{l}\text { Mesin las } \\
\text { SMAW 70- } \\
80 \mathrm{~A} \\
\end{array}$ & 1. & $\begin{array}{l}\text { Batu gerinda } \\
\text { tangan flat wheel } \\
\text { dan cutter wheel }\end{array}$ \\
\hline 2. & Topeng las & & $\begin{array}{l}\text { Elektroda RB-26 } \\
\text { 2,6 mm }\end{array}$ \\
\hline 3. & $\begin{array}{l}\text { Sarung } \\
\text { tangan } \\
\text { safety }\end{array}$ & & $\begin{array}{l}\text { Cat warna biru } \\
\text { langit }\end{array}$ \\
\hline 4. & $\begin{array}{l}\text { Gerinda } \\
\text { tangan uk. } 4 \\
\text { inchi }\end{array}$ & 4. & Rubber pad \\
\hline 5. & Penitik & & $\begin{array}{l}\text { Besi siku } 5 \text { x } 5 \\
\mathrm{~cm} \text { (panjang } 6 \mathrm{~m} \text { ) }\end{array}$ \\
\hline 6. & $\begin{array}{l}\text { Penggaris } \\
\text { besi }\end{array}$ & & Ram mesh 3 mm \\
\hline 7. & $\begin{array}{l}\text { Penggaris } \\
\text { siku }\end{array}$ & & $\begin{array}{l}\text { Pulley } 14 \text { inchi } \\
\text { dan v-belt }\end{array}$ \\
\hline 8. & Meteran & & Drum 200 liter \\
\hline 9. & $\begin{array}{l}\text { Jangka } \\
\text { sorong }\end{array}$ & & $\begin{array}{l}\text { Plat besi tebal } 4 \\
\text { mm }\end{array}$ \\
\hline & & & $\begin{array}{l}\text { Pillow block } \\
\text { (bearing) Ø } 35 \\
\text { mm }\end{array}$ \\
\hline & & 11. & $\begin{array}{l}\text { Shaft } 900 \mathrm{~mm} \varnothing \\
35 \mathrm{~mm}\end{array}$ \\
\hline & & 12. & $\begin{array}{l}\text { Motor bensin 5,5 } \\
\text { PK }\end{array}$ \\
\hline \multicolumn{4}{|c|}{ (Sumber: Dokumentasi Pribadi) } \\
\hline \multicolumn{4}{|c|}{$\begin{array}{l}\text { Proses pengukuran merupakan proses } \\
\text { sangat penting karena berpengaruh } \\
\text { dap hasil dari setiap komponen-komponen } \\
\text { dibuat. Berikut ini merupakan proses } \\
\text { akuran yang dilakukan dalam pembuatan } \\
\text { pengupas kulit lada menggunakan cutter } \\
\text { er pad: }\end{array}$} \\
\hline
\end{tabular}

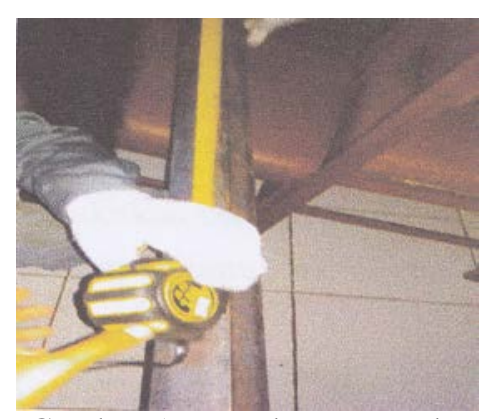

Gambar 5. Pengukuran Rangka (Sumber: Dokumentasi Pribadi)

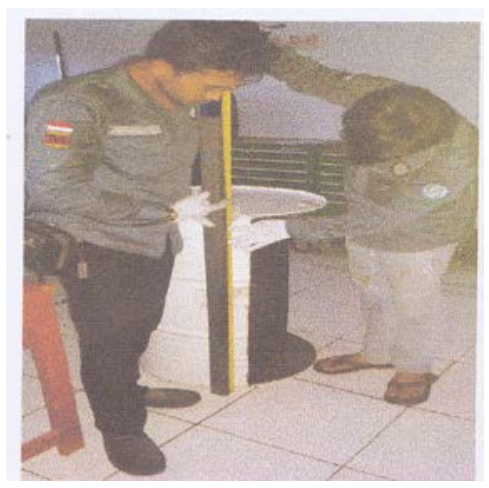

Gambar 6. Pengukuran Drum (Sumber: Dokumentasi Pribadi)
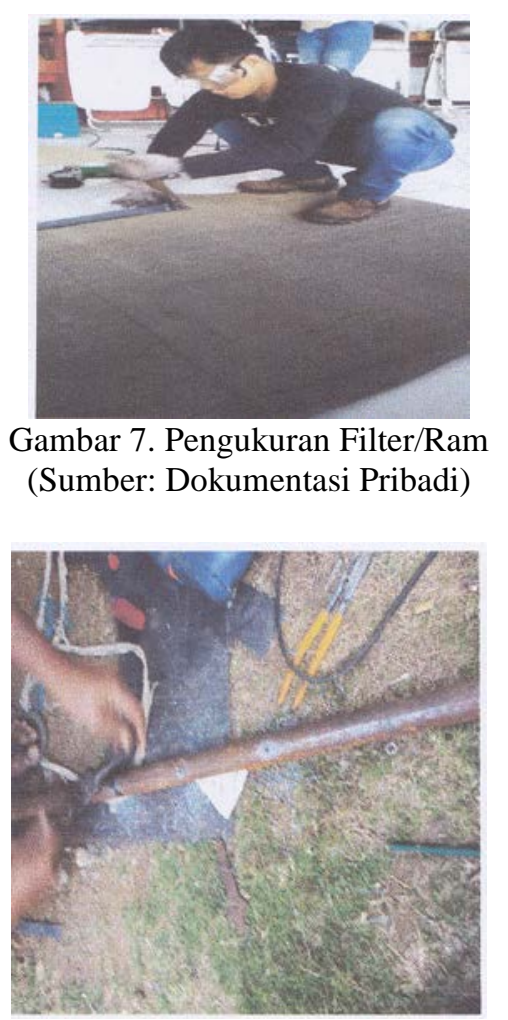

Gambar 8. Pengukuran Poros (Sumber: Dokumentasi Pribadi) 


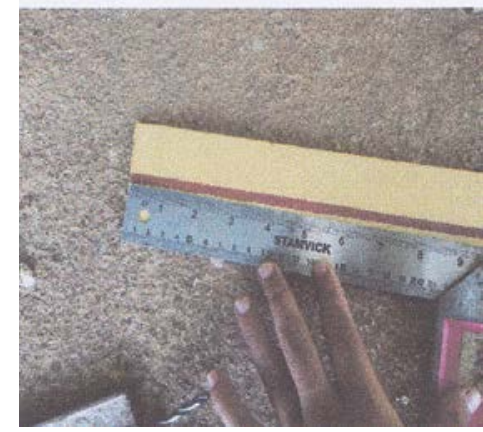

Gambar 9. Pengukuran Karet (Sumber: Dokumentasi Pribadi)

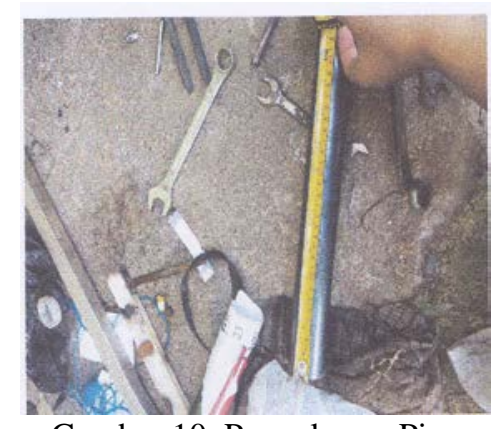

Gambar 10. Pengukuran Pipa

(Sumber: Dokumentasi Pribadi)

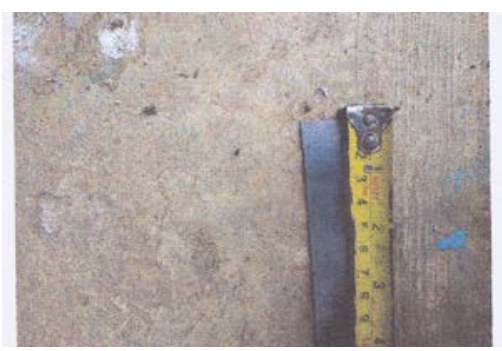

Gambar 11. Pengukuran Plat Strip (Sumber: Dokumentasi Pribadi)

Setelah dilakukan proses pengukuran, langkah selanjutnya adalah proses pemotongan. Berikut merupakan proses pemotongan pada komponen-komponen mesin pengupas kulit lada menggunakan cutter rubber pad:

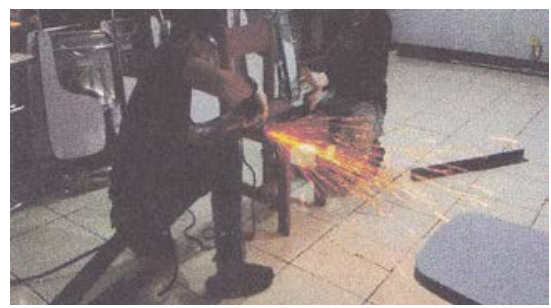

Gambar 12. Pemotongan Rangka (Sumber: Dokumentasi Pribadi)

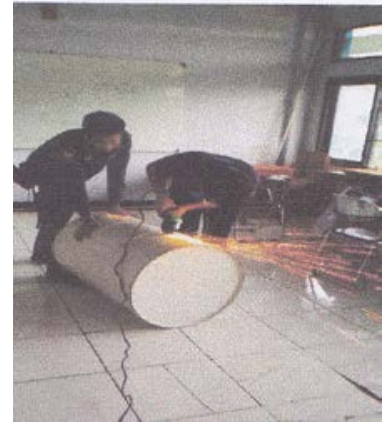

Gambar 13. Pemotongan untuk Pembuatan Cover (Sumber: Dokumentasi Pribadi)
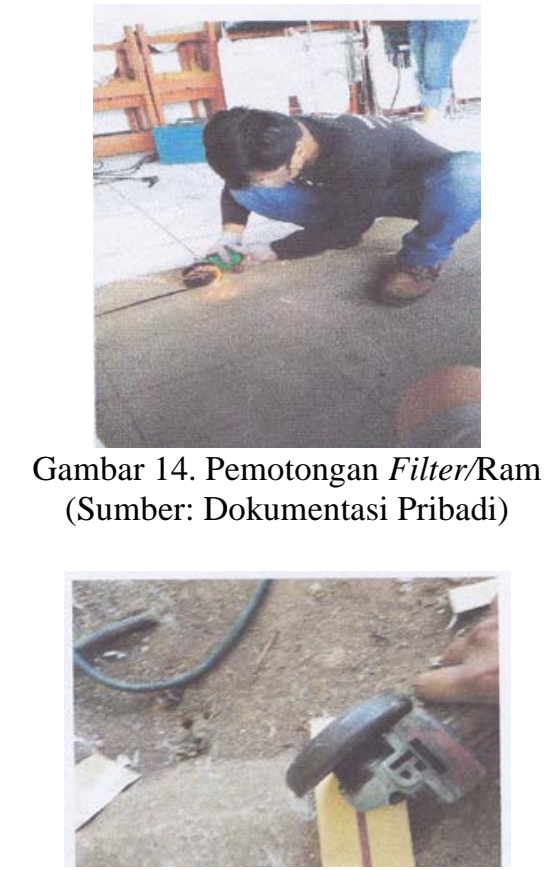

Gambar 15. Pemotongan Rubber Pad (Sumber: Dokumentasi Pribadi)

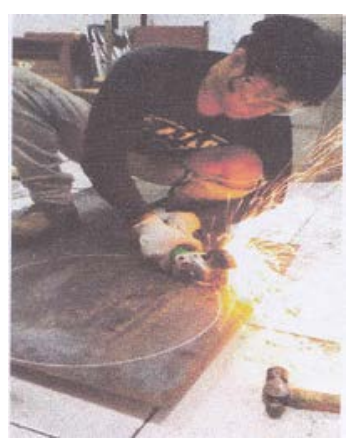

Gambar 16. Pemotongan untuk Plat Roda (Sumber: Dokumentasi Pribadi)

Setelah proses pemotongan selesai, langkah selanjutnya adalah proses pengelasan dengan las SMAW menggunakan elektroda RB26 dengan arus 60-70 Ampere dan penyambungan menggunakan mur dan baut. 
Berikut merupakan proses penyambungan yang dilakukan:

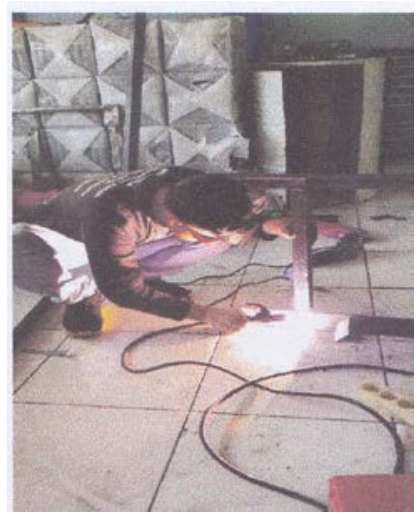

Gambar 17. Penyambungan Rangka (Sumber: Dokumentasi Pribadi)

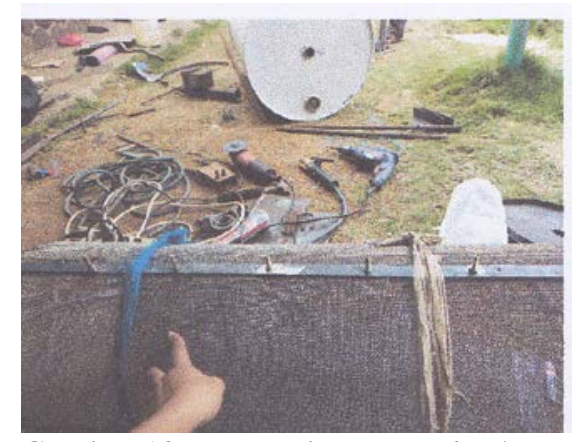

Gambar 18. Penyambungan Filter/Ram menggunakan Mur dan Baut (Sumber: Dokumentasi Pribadi)

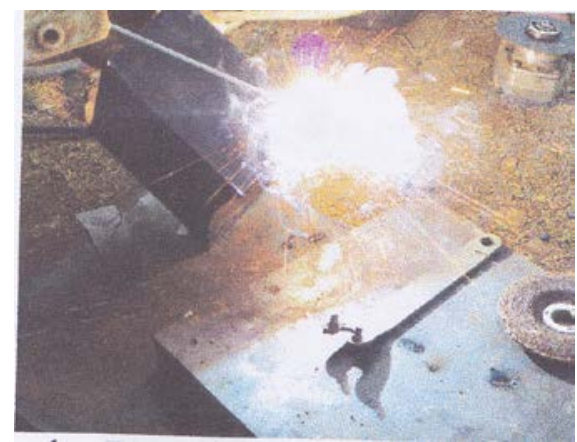

Gambar 19. Penyambungan Tutup Saluran Output (Sumber: Dokumentasi Pribadi)

Langkah selanjutnya adalah proses perakitan atau assembly adalah penggabungan semua komponen yang telah dibuat dalam proses manufaktur hingga menjadi produk yang utuh. Perakitan pada mesin ini menggunakan mekanisme pengelasan dan sambungan mur dan baut. Langkah selanjutnya setelah proses perakitan adalah proses finishing, meliputi: penggerindaan halus, amplas, pemolesan dan pengecatan.

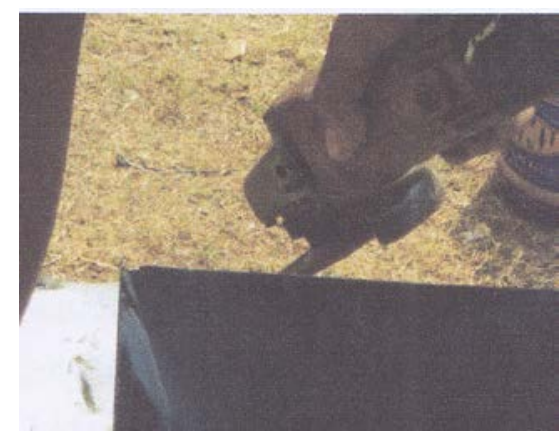

Gambar 20. Proses Penggerindaan halus (Sumber: Dokumentasi Pribadi)

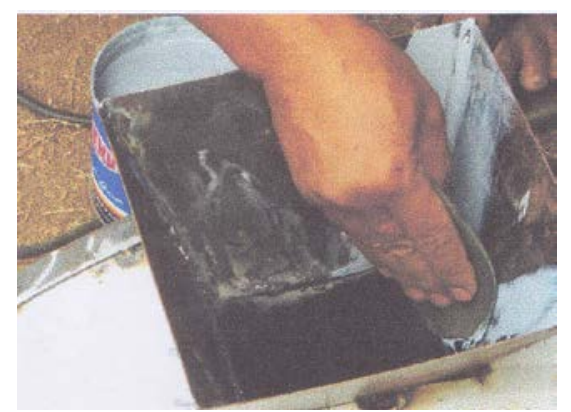

Gambar 21. Proses Pemolesan

(Sumber: Dokumentasi Pribadi)

Langkah terakhir dari proses manufaktur mesin ini adalah uji kinerja di mana proses ini dilakukan untuk mengetahui kekurangan dan kelebihan dari mesin pengupas lada. Uji kinerja dilakukan sebanyak dua kali, dengan tahapan yang pertama yakni proses pemasukan lada. Pengupasan dilakukan dua kali di mana pengupasan pertama bertujuan untuk memisahkan tangkai lada dengan bijinya dan pengupasan kedua untuk pengupasan biji lada dengan kulit.

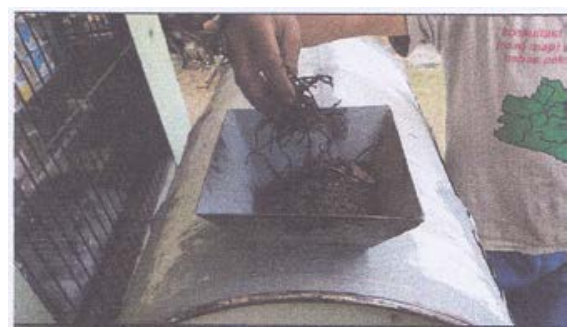

Gambar 22. Proses Memasukkan Lada (Sumber: Dokumentasi Pribadi)

Tahapan kedua yakni proses pengisian air. Proses pengisian air bertujuan agar pada saat dilakukan pengupasan lada lebih cepat terpisah dari kulitnya dan mencegah terjadinya 
kerusakan pada biji lada. Hasil pengupasan lada ditunjukkan pada Gambar 24.

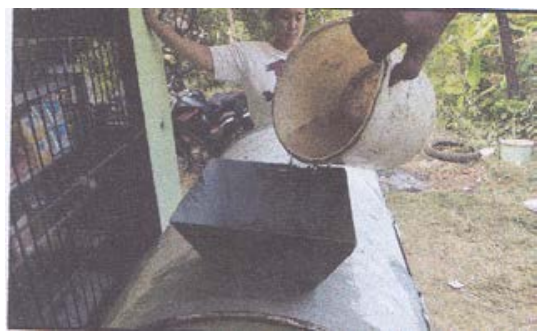

Gambar 23. Proses Pengisian Air (Sumber: Dokumentasi Pribadi)

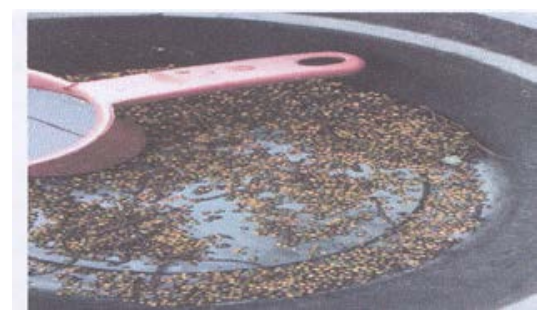

Gambar 24. Hasil Pengupasan Lada (Sumber: Dokumentasi Pribadi)

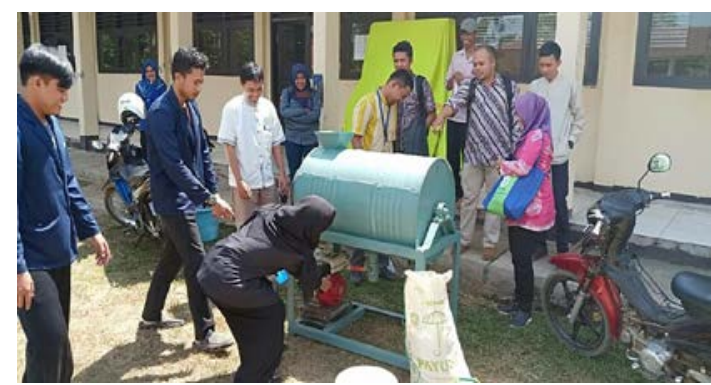

Gambar 25. Proses Uji Kinerja Mesin Pengupas Kulit Lada menggunakanCutter Rubber Pad

(Sumber: Dokumentasi Pribadi)

Hasil dari uji kinerja diperoleh kapasitas mesin pengupas kulit lada menggunakan cutter rubber pad yaitu $28 \mathrm{~kg} / \mathrm{jam}$ dan daya mesin sebesar 1,6 liter/jam dengan kecepatan 3600 rpm. Kulit lada dapat terkupas tanpa harus direndam terlebih dahulu sehingga dapat meningkatkan produktivitas petani lada. Sedangkan kekurangan dari mesin ini adalah belum terdapat pelindung pada bagian pulley dan $v$-belt nya sehingga dapat membahayakan operator.

\section{SIMPULAN}

Hasil rancang bangun mesin pengupas kulit lada menggunakan cutter rubber pad yaitu mesin dapat berfungsi melakukan pengupasan kulit lada tanpa perlakuan perendaman sebelumnya. Spesifikasi mesin ini yakni: dimensi panjang $993 \mathrm{~mm}$, lebar $590 \mathrm{~mm}$, tinggi $670 \mathrm{~mm}$, dan daya motor 5,5 HP dengan putaran 3600 rpm serta kapasitas mesin 28 $\mathrm{kg} / \mathrm{jam}$.

\section{DAFTAR RUJUKAN}

Almizan. 2017. Rancang Bangun Mesin Pengupas Kulit Lada Tipe Tirus Putaran Vertikal berdasarkan Metode Nordic Body Map (NBM) dan Pendekatan Antropometri. Jurnal TIN Universitas Tanjungpura. Volume 1. Nomor 3, 13-18.

Ashby, M. F. 2005. Materials Selection in Mechanical Design. Third Edition. Italy: Elsevier, Butterworth Heinemann.

Firlya Rosa, Rodiawan, Saparin. 2018. Rancang Bangun Pengupas Biji Lada menggunakan Sistem Crusher. Jurnal Ipteks Terapan. Volume 12. Nomor 2, 177-183.

Maizar Rizki. 2015. Rancang Bangun Mesin Pengupas Lada Tipe Piringan dengan menggunakan Metode Ethnography dan Kansei Engineering. Jurnal TIN Universitas Tanjungpura. Volume 1. Nomor 3, 19-23.

Rivandra Rezani. 2018. Teknologi Mekanik: Panduan Aplikatif Mahasiswa Vokasi. Subang: POLSUB Press.

Rusli, S. 1996. Pengolahan dan penyimpanan lada. Monograf Tanaman Lada No. 1. Balai Penelitian Tanaman Rempah dan Obat. Bogor. 188-194.

Suhendra, Abdul Rozaq, Bambang Purwantana. 2010. Rancang Bangun dan Pengujian Mesin Pengupas Lada (Piper Nigrum L.) Tipe Silinder Putaran Vertikal. Prosiding Seminar Nasional PERTETA Unsoed Purwokerto 2010.

Susilawati \& Azhis Sholeh Buchori. 2019. Design and Application of Special Service Tools (SST) for Telescopic Front 
Fork. Automotive Experiences. Volume 2. Nomor 2, 53-58.

Susilawati, Azhis Sholeh Buchori, Oyok Yudiyanto. 2019. Proses Manufaktur Alat Bantu Khusus (Special Service Tools) Pelepas Seal Suspensi Depan Jenis Telescopic Fork Sepeda Motor. Jurnal Ilmiah Ilmu dan Teknologi Rekayasa. Volume 2. Nomor 1, 21-25.

Sri Usmiati \& Nanan Nurdjannah. (2006). Pengupasan Kulit Buah Lada dengan Enzime Pektinase. Jurnal LITRI, Badan Penelitian Tanaman Rempah dan Minyak Astiri, Balai Penelitian Tanaman Rempah dan Minyak Atsiri, Bogor. Volume 12. Nomor 2, 80-86.
Tatang Hidayat, Nanan Nurdjannah, Sri Usmiati. 2009. Analisis Teknis dan Finansial Paket Teknologi Pengolahan Lada Putih (White Pepper) Semi Mekanis. Buletin Litro. Balai Besar Penelitian dan Pengembangan Pascapanen Pertanian. Volume 20. Nomor 1, 77-91.

Yosini Deliana, Eliana Wulandari, Endah Djuendah. 2018. Pengentasan Kemiskinan melalui Pengembangan Ekonomi Kreatif Perdesaan Berbasis Potensi Lokal di Kabupaten Sumedang. Jurnal Social Economic of Agriculture. Volume 7. Nomor 2, 105-115. 